\title{
Hábitos alimentares regionais no Programa Nacional de Alimentação Escolar: um estudo qualitativo em um município do sertão da Bahia, Brasil ${ }^{1}$
}

\section{Regional food habits in the Brazilian National \\ School Food Program: a qualitative approach \\ in a town of the Brazilian caatinga}

Janaína Braga de PAIVA²

Maria do Carmo Soares de FREITAS²

Lígia Amparo da Silva SANTOS²

RE S U M O

\section{Objetivo}

O estudo, de abordagem qualitativa, buscou interpretar os significados do termo "hábitos alimentares regionais" e as acepções acerca do respeito a esses hábitos no âmbito do Programa Nacional de Alimentação Escolar.

\section{Métodos}

A produção dos dados deu-se por meio da realização de entrevistas semiestruturadas com os atores envolvidos nesse programa em um município do sertão baiano.

\section{Resultados}

Os resultados e a discussão abordaram as acepções relacionadas a esses hábitos e as justificativas da importância de respeitá-los. Estas acepções expressaram-se de forma polissêmica, suscitando temáticas como tradições alimentares, alimentação saudável, racionalidade técnica e êmica, aceitabilidade da alimentação escolar e segurança alimentar e nutricional.

1 Artigo elaborado a partir da dissertação de JB PAIVA, intitulada "Hábitos alimentares regionais no âmbito do Programa Nacional de Alimentação Escolar em um município do sertão baiano: uma abordagem qualitativa". Universidade Federal da Bahia; 2011.

${ }^{2}$ Universidade Federal da Bahia, Escola de Nutrição, Núcleo de Estudos e Pesquisas em Alimentação e Cultura. R. Araújo Pinho, 32 Canela, 40110-150, Salvador, BA, Brasil. Correspondência para/Correspondence to: JB PAIVA. E-mail: <janainapaiva@ufba.br>. 
192 | JB PAIVA et al.

\section{Conclusão}

Verificou-se carência de conceitos acerca do tema no âmbito científico-acadêmico e que está implícita na instância do programa uma correlação de forças que visam à conformação de novos hábitos alimentares sob a égide da alimentação saudável e a preservação do que se convenciona chamar de hábitos alimentares regionais.

Termos de indexação: Alimentação escolar. Hábitos alimentares. Políticas públicas. Segurança alimentar e nutricional

\section{A B S T R A C T}

\section{Objective}

This qualitative study tried to interpret the meanings of the term "regional food habits" and the notions of respect for these habits by the National School Food Program.

\section{Methods}

Data were collected by semi-structured interviews with members of this program in a municipality in the caatinga region of Bahia.

\section{Results}

The results and discussion cover the notions associated with these habits and the reasons that explain the importance of respecting them. These notions were expressed in a polysemic way, raising themes such as food traditions, healthy food habits, technical and emic rationality, school food acceptability and food and nutritional security.

\section{Conclusion}

There is a gap in the literature regarding concepts on the topic and a correlation of forces that try to develop new, health-oriented food habits. The preservation of what is conventionally called 'regional food habits' is implicit in the scope of the program.

Indexing terms: School feeding. Food habits. Public policy. Food security.

\section{N T R O D U ÇÃ O}

O Programa Nacional de Alimentação Escolar (PNAE), um dos programas sociais mais antigos do País, tem um sólido arcabouço legal que visa a contribuir, por meio da oferta de uma alimentação saudável e adequada, com o crescimento e o desenvolvimento de escolares matriculados na educação básica das redes públicas, incluindo os que se encontram em áreas indígenas e de remanescentes quilombolas. Dentre inúmeros aspectos, essa alimentação compreende a utilização de alimentos variados e seguros e referencia-se no respeito à cultura, hábitos e tradições alimentares $^{1,2}$. No âmbito do programa, o princípio que explicita a necessidade do respeito aos hábitos alimentares regionais é enfatizado como relevante para que os seus propósitos sejam alcançados.

Considerando-se o histórico do Programa, Spinelli \& Canesqui ${ }^{3}$ situam que o sistema centra- lizado de aquisição de gêneros alimentícios afetou a operacionalização e a eficácia dos resultados do PNAE, já que a alimentação escolar oferecida não condizia com os hábitos dos alunos devido à padronização dos cardápios, a qual se relacionava a um sistema que envolvia, por exemplo, a cartelização dos fornecedores. Segundo as autoras, foi a partir da passagem gradativa do modelo centralizado para o descentralizado, em especial a partir da década de 1990, que houve maior estímulo para aquisição de alimentos básicos e in natura dos produtores locais, cuja pretensão é, dentre outras, favorecer a aproximação do cardápio fornecido aos hábitos alimentares dos escolares $^{3}$.

Compactuando com a necessidade de aproximação dos cardápios aos hábitos alimentares dos escolares para que se concretize o objetivo do PNAE no que se refere à oferta de uma 
alimentação saudável e adequada, encontra-se o estímulo ao respeito aos hábitos alimentares regionais como capazes de possibilitar essa aproximação. Salienta-se que o processo de globalização, por meio da homogeneização e padronização em diversas ordens, a exemplo das práticas alimentares, contribuiu para um movimento de valorização e reafirmação das especificidades locais, o qual está vinculado ao fortalecimento das identidades sociais e seus signos de identificação. Nesse contexto, consolida-se a concepção do respeito à diversidade cultural e aos hábitos alimentares regionais.

Vale sinalizar que o termo "hábitos alimentares regionais" não está assim registrado na legislação vigente - Lei 11.947 de junho de 2009', que dispõe sobre o atendimento da alimentação escolar. A lei faz referência aos termos "local" ou "da localidade", como pode ser exemplificado no Art. $12^{\circ}$ apresentado a seguir:

Os cardápios da alimentação escolar deverão ser elaborados pelo nutricionista responsável com a utilização de gêneros alimentícios básicos, respeitando-se as referências nutricionais, os hábitos alimentares, a cultura, e a tradição alimentar da localidade, pautando-se na sustentabilidade e diversificação agrícola da região, na alimentação saudável e adequada (grifos dos autores).

Entretanto, normas do Ministério da Educação e Cultura, correspondentes à execução do Programa na década de 1990, referem-se à "adequação dos cardápios aos hábitos alimentares regionais" 4 como um dos seus objetivos. A utilização de tal termo foi observada também em artigos científicos publicados recentemente no campo da Alimentação e Nutrição, como o artigo de Chaves et al..$^{5}$ intitulado "O Programa Nacional de Alimentação Escolar como promotor de hábitos alimentares regionais" e na descrição do histórico do PNAE apresentado no site do Fundo Nacional de Desenvolvimento da Educação (FNDE) ${ }^{6}$ no período de realização deste estudo.
Sobre essa temática aparentemente simples, surge na retórica discursiva do Estado a imagem do "respeito aos hábitos alimentares regionais e à vocação agrícola do município, fomentando o desenvolvimento da economia local" . Vale salientar que esse enunciado representa um dos principais avanços políticos do PNAE desde os últimos anos na medida em que valoriza o setor primário de produção do município. Segundo Belik \& Chaim7, a administração descentralizada possibilitou racionalizar a logística e os custos de distribuição dos produtos, bem como proporcionou a inserção da pequena empresa, do comércio local, do pequeno produtor e da pecuária local no mercado da alimentação escolar.

Tendo em vista o reconhecimento do termo no âmbito acadêmico e institucional - embora na legislação vigente esteja enfatizada a perspectiva do local -, ele será utilizado como referência no presente estudo. Para a análise das informações obtidas e produzidas em campo, entendeu-se de início a similitude entre os sentidos de alimentação regional e local, particularmente no que concerne à territorialidade dos alimentos. $\mathrm{O}$ termo local pode ser entendido como contido no escopo do regional, estando imbricada no seu sentido a concepção de um locus onde a produção dos alimentos é materializada.

Em relação à noção do termo regional, compreende-se na intersubjetividade a perspectiva simbólica das preparações e da construção de cardápios para os escolares, por associar-se à imagem da cozinha regional, que, vinculada aos sentidos do típico e da tradição, contempla outras dimensões espaciais, a exemplo do receituário culinário do sertão e do nordeste, indo para além do território oficial do município.

Vale sinalizar que no campo de pesquisas sobre o PNAE são pouco estudadas as interpretações relacionadas ao princípio de respeito aos hábitos alimentares regionais, especialmente sob a ótica da pesquisa qualitativa. No que tange a esses hábitos, destaca-se a carência de conceitos no âmbito científico-acadêmico que possam subsidiar as ações dos profissionais inseridos no con- 
texto do programa. Portanto, tendo em vista que tal temática trata de uma lacuna importante na literatura, o presente estudo procurou interpretar os significados do termo "hábitos alimentares regionais" e as acepções acerca do respeito a esses hábitos no âmbito do PNAE em um município do sertão baiano.

Este estudo foi desenvolvido no município de Valente, situado na área denominada "Polígono das Secas", localizado a 237 quilômetros da cidade de Salvador, na região nordeste do Estado da Bahia. Sustenta uma vegetação do tipo caatinga arbórea aberta, com exemplares do popularmente conhecido mandacaru. A agricultura da região é de subsistência, produtora de gêneros alimentícios como milho, feijão, mandioca, batata-doce, abóbora, quiabo, umbu e cajá, sendo sua principal economia a agropecuária, destacando-se a caprinocultura e a produção do sisal. Valente possui 42 comunidades, incluindo fazendas e povoados, com 24560 habitantes em 2010, segundo dados do $\mathrm{IBGE}^{8}$.

\section{MÉTODOS}

Trata-se de uma pesquisa qualitativa desenvolvida no município de Valente (BA). O critério para a escolha do município pautou-se no fato de o PNAE encontrar-se estruturado de acordo com a legislação vigente, e no apoio da nutricionista responsável que referiu ter regionalizado os cardápios no último ano. Em 2009, houve interlocução com a Secretaria Municipal de Educação para a autorização da pesquisa. O trabalho de campo ocorreu entre os meses de abril e julho de 2010, com registros da observação de campo e de entrevistas semiestruturadas ou em profundidade, quando a sensibilidade para observar e escutar é parte do rigor da pesquisa qualitativa ${ }^{9}$. A produção desses dados faz parte de um projeto maior, concebido nos principais cenários de execução do programa, dentre os quais estão as unidades de ensino. Ressalta-se para tanto a relevância dos diários de campo como material com- plementar para a interpretação dos dados elucidados nas entrevistas.

Foram realizadas entrevistas semiestruturadas com a coordenadora da alimentação escolar, a nutricionista responsável pela alimentação escolar do município, a presidente do Conselho de Alimentação Escolar (CAE), três diretoras e três merendeiras das unidades de ensino, sendo duas da zona urbana e uma da zona rural para cada profissão. Vale sinalizar que todas as entrevistas foram realizadas com mulheres, embora esse não tenha sido um critério de seleção, mas um fator propiciado pelo contexto: os cargos ocupados estavam sob responsabilidade de pessoas do sexo feminino.

A entrevista como instrumento para produção de dados auxilia no fornecimento de informações que se relacionam a maneiras de pensar, sentir e atuar, condutas, crenças, opiniões, razões conscientes ou inconscientes sobre o objeto da pesquisa. A entrevista semiestruturada combina questões pré-estabelecidas e abertas, o que possibilita ao entrevistado discorrer sobre o assunto proposto, sem se prender à indagação formulada ${ }^{10}$. As falas oriundas das entrevistas foram devidamente gravadas e transcritas, e as identidades das protagonistas, protegidas quando seus nomes não foram revelados.

Um processo de leitura acurada do material produzido foi fundamental para a construção das categorias de análise e para a organização dos dados de acordo com essas categorias, que foram sistematizadas em: o que vem a ser do hábito alimentar regional, porque é importante respeitar esses hábitos e as concepções relacionadas à alimentação saudável.

Salienta-se que questões éticas com base na Resolução CNS 196/96"11 foram devidamente consideradas para realização deste projeto de pesquisa, que foi aprovado pelo Comitê de Ética em Pesquisa da Escola de Nutrição da Universidade Federal da Bahia, parecer número 28/09. Todas as entrevistadas assinaram o termo de consentimento livre e esclarecido. 


\section{RESULTADOSE DISCUSSÃO}

\section{Sobre os significados de "hábitos alimentares regionais"}

O que é mesmo entendido como hábitos alimentares regionais? Quais alimentos e preparações compõem esses hábitos? Essas foram algumas questões motivadoras do presente estudo.

A partir das entrevistas realizadas, tomando-se em especial como exemplo as preparações programadas nos cardápios da alimentação escolar para o ano de 2010, ficaram explícitas as diversas interpretações relacionadas ao termo "hábito alimentar regional". No contexto das falas, a referência unânime para o significado do termo "regional" é aquela na qual o alimento é produzido/plantado/colhido/fabricado na localidade. Nesse sentido, a utilização do termo "da terra", designado para alguns gêneros alimentícios produzidos no município, é significante, como, por exemplo, "batata da terra" e "frango da terra", conhecidos também como "batata-doce" e "galinha caipira" respectivamente.

O leite e o feijão também foram mencionados pelas entrevistadas como alimentos regionais - produzidos na região - e habitualmente consumidos nas combinações feijão com arroz e café com leite. Para algumas, essas preparações seriam do hábito alimentar regional por serem muito consumidas no cotidiano pela população como um todo, além de parte dos seus ingredientes serem "da região". Contudo, para outras, essas combinações não seriam do hábito alimentar regional, pois "não é só daqui", "é de todos os municípios" e, portanto, seriam do consumo nacional. A professora Nina, diretora de uma das escolas da zona urbana, ponderou que o feijão com arroz seria "digamos... uma cultura regional, não exclusiva".

Nas entrevistas, notou-se também que todas as informantes consideravam o milho e seus derivados como pertencentes ao hábito alimentar regional. Além de ele ser plantado na localidade, seus derivados - dentre os quais mungunzá, mingau de fubá e canjica - foram associados especialmente à "mesa do São João", à "mesa do típico", sendo o cuscuz associado ao consumo cotidiano: "tem todos os dias na mesa do Valentense"

Já o iogurte foi considerado um produto regional por ter passado a ser fabricado no município e também em cidades vizinhas, como afirma dona Rebeca, merendeira da escola da zona rural: "antes não era (regional), mas agora é". Entretanto, a partir dos diálogos estabelecidos com as entrevistadas, foi possível questionar se tal produto compõe o hábito alimentar regional e, consequentemente, se existe a possibilidade de um alimento compreendido como regional não fazer parte do hábito alimentar regional.

Reflete-se a partir disso sobre a possibilidade de um produto ser considerado regional, mas não tradicional, levando-se em consideração sua recente produção e consumo no município. Destaca-se, nesse sentido, que o uso de alimentos produzidos na região não faz de uma refeição em si algo da tradição alimentar, pois nesta está implícita uma combinação de fatores como ingredientes, acompanhamentos, lugar e hora que marcam a comensalidade.

Observa-se que o hábito alimentar regional pode ser entendido por um lado como algo que é específico/exclusivo da região e que não é consumido em outros lugares. Esse sentido emerge especialmente quando se contextualiza os produtos e preparações consumidos em nível nacional. Para tal acepção, deve-se considerar a dicotomia entre o alimento produzido na localidade e aquele trazido de outro lugar, "vindo de fora". Vale situar ainda que na instância do hábito alimentar regional pode estar compreendido um alimento ou preparação considerado do consumo diário para toda população da localidade ou região, mesmo que ele faça parte do que se entende como hábitos alimentares de outras regiões.

No decorrer das entrevistas, os testemunhos mostram que "hábito" se configura co- 
mo uma palavra que invoca o sentido de cotidiano ou de costume, e, no campo semântico, referenciam o consumo habitual como representativo do hábito alimentar regional, assim como se apresenta a imagem do alimento produzido na região. Quando discorrem acerca do hábito alimentar, imediatamente se referem ao que se come no lugar, na região, e mencionam os diversos tipos de alimentos e preparações. Nesse sentido, torna-se relevante a delimitação entre os gêneros alimentícios e as preparações regionais, considerando-se que nem toda preparação dita regional é feita com "alimentos regionais", como no caso do arroz-doce, em que o arroz é produzido "fora" da região.

Com base em tal noção, vale recordar que cultura, tradição e identidade são produtos históricos que se configuram como entidades dinâmicas, instáveis e desencadeadas por fenômenos complexos de troca. Os modelos e as práticas alimentares são frutos da circulação de homens, mercadorias, técnicas e gostos ${ }^{12}$. Assim, vale sinalizar que as tradições culinárias de uma região podem ser consolidadas a partir da utilização de ingredientes de outras localidades. Nesse sentido, de acordo com Montanari12, a tradição alimentar pode se desenvolver em locais distantes de suas origens.

As entrevistadas informam sobre o que não é fabricado na região ou o que surgiu recentemente, como a soja utilizada na alimentação escolar. Para Dona Marisa, uma das merendeiras, "é difícil o povo daqui usar soja. Só se for por doença". Conforme outros testemunhos, a nutricionista "incrementou" preparações "que não faziam parte do dia a dia das crianças da escola".

Nessa instância, entendemos ser possível questionar qual o limite para a manipulação de uma receita tradicional sem descaracterizá-la, tomando-se como exemplo o caso da soja mencionado acima, que embora seja considerada saudável, em geral não é bem aceita na comunidade escolar. Sinaliza-se que a lógica nutricional, a qual implica o equilíbrio entre os diversos nutrientes nas preparações, pode não coadunar com a cultura alimentar, não sendo suficiente, portanto, para que o alimento seja aceito. Situa-se aqui a perspectiva considerada no campo da antropologia da alimentação, na qual o consumo de alimentos pelos indivíduos se dá muito além da mera escolha de alimentos como fonte de nutrientes.

Na entrevista de dona Marisa, observa-se uma associação intrínseca entre a noção de regional e saudável. Os termos se confundem e ganham importância porque simbolizam a condição de "natural" ou da "natureza". Para ela, hábito alimentar regional significa "costume da gente", "comidas típicas", ou o que é próprio, pertencente à comunidade, sendo por isso "saudável e natural". Ela elenca os seguintes produtos: mandioca, farinha, tapioca, milho, carneiro e frango da terra, e lembra que a comida de antes (ou tradicional) está voltando. Há uma espécie de resistência para manter o que se concebe como valor social da produção da terra e da culinária. Nesse âmbito, a alimentação saudável é aqui interpretada pelos entrevistados como da "natureza", produto da localidade que gera confiança quanto à maneira de plantar, pois "a gente está vendo". A desconfiança do uso de produtos de outras regiões está ancorada na utilização de agrotóxicos. Quando pontuam "aqui se cresce na natureza" (desenvolve-se naturalmente), elucidam a necessidade que têm em reafirmar a concepção de "natureza pura" ou "natural" ao falar de si, de seus produtos, de suas identidades como "filhos da terra". Há, pois, um emaranhado de conceitos que se cruzam com a terminologia saudável.

Desse modo, em geral, entende-se que os hábitos alimentares tradicionais e a alimentação com produtos da região estão vinculados à "melhoria de vida", sendo por isso "mais saudáveis". Entretanto, muitas vezes uma alimentação saudável pode ser rejeitada pelos escolares que, segundo afirmam, gostam de "coisas supérfluas", como cachorro quente e hambúrguer.

Tais considerações fazem semelhanças com os sentidos atribuídos aos alimentos indus- 
trializados (carnes embutidas, achocolatados etc), que, não sendo originalmente um hábito alimentar regional, são considerados elementos da "cultura da globalização", como expressa a nutricionista. Assim, esses alimentos e suas preparações são criações recentes, não saudáveis e por fim não regionais. Em contraposição a essa lógica alimentar, tem-se o hábito alimentar regional diretamente vinculado ao saudável, ao passado, ao tradicional, à herança e à cozinha da região. Nesse aspecto, pode-se dizer que os significantes elucidados neste estudo relacionam-se com as concepções de hábitos alimentares regionais e não regionais numa complexa combinação entre termos que se atraem e se afastam, confundem-se na dimensão semântica, como produtos de fora, estranhos, naturais, saudáveis, da terra ou da região.

As concepções circunscrevem a desconfiança dos indivíduos quanto ao alimento industrializado, sinalizado por Fischler ${ }^{13}$ como o impuro e o artifício. Para esse autor, o alimento industrializado tornou-se um artefato misterioso que não é mais operado por "mão familiar e em condições sob suspeitas purificadas pelo amor e rito". A indústria faz uma "obscura cozinha", encarnando uma "mãe malvada" que trabalha mais com obscuras manipulações - o caldeirão da bruxa - do que com uma alquimia suculenta.

Ao contrário, quanto ao alimento natural, conforme estudo de Lisfchitz ${ }^{14}$, há uma multiplicidade de definições que requer um processo de reclassificação simbólica dos alimentos. O alimento natural pode estar associado à maneira como é originado, isto é, a uma produção artesanal na terra, na própria natureza. Assim, não são reconhecidos como naturais os alimentos produzidos com agrotóxicos ou "aditivos químicos" e os industrializados. Segundo o autor, o alimento natural pode estar inserido também no discurso da "boa alimentação", representando um conjunto de nutrientes adequados às necessidades fisiológicas do organismo humano.

Santos $^{15}$ aponta para a mitificação da natureza ao parafrasear Lucien Sfez. A autora propõe o "mito do alimento perfeito", representado como natural e detentor, de maneira equilibrada, de todos os nutrientes necessários, sendo criado para um mundo estável e harmônico, imortalizado por técnicas que garantam sua não senilidade e higienizado para que não provoque doenças. Nessa instância, inscreve-se também a construção de um "corpo perfeito", que acompanha a "dieta perfeita", corporificada na constituição da alimentação saudável como um caminho para a "saúde perfeita", relacionada à assepsia dos corpos livres de todos os males e doenças.

Ainda nessa esteira de interpretação do "alimento natural", as pesquisadoras Carvalho \& Luz $^{16}$, em estudo que objetivou aprofundar os significados construídos nas práticas alimentares reprodutoras do estilo "natural" e do estilo fast-food, sinalizam a concepção do "natural" como um construto simbólico inerente à pós-modernidade, a qual emerge no contexto dos pós-guerras mundiais. Em tal concepção, está implicada a rejeição de um ideal de modernidade, a qual se contrapõe à disposição para uma agricultura menos intensiva e promotora do desenvolvimento social. As autoras contextualizam que esse modelo de produção é oposto à perspectiva desenvolvimentista capaz de propiciar maior concentração de riqueza e acirrar a desigualdade social no Brasil. Nessa perspectiva, apresentam o "mal-estar cultural" simbolizado no estilo fast-food, cuja produção em larga escala é compreendida como depredadora, enquanto o "natural" é apresentado como não poluidor da natureza, indicando resistência ao processo de industrialização e urbanização acelerado.

\section{Sobre as acepções do "respeito aos hábitos alimentares regionais"}

A perspectiva que vincula os hábitos alimentares regionais à imagem do sadio e da alimentação saudável contribui para justificar a importância do respeito como um valor no âmbito do PNAE. Segundo a coordenadora da alimen- 
tação escolar, respeitá-los possibilita que "a criança fique bem alimentada" e ainda contribui para que o aluno passe a ter conhecimento sobre como está se alimentando, podendo, assim, "evitar futuros problemas de saúde". Para ela é também importante porque "são coisas que a gente tem conhecimento de onde vem, ... a gente sabe que é uma alimentação sem tóxico... é uma coisa mais sadia".

De acordo com a nutricionista, o respeito aos hábitos alimentares regionais promoveria o resgate de "hábitos saudáveis da alimentação regional", sendo este um dos papéis da alimentação escolar. Ela considera que as gerações anteriores "tinham acesso a muito menos coisas industrializadas, comiam coisas muito mais naturais...", sendo esses hábitos compreendidos como uma alimentação saudável. Assim, ressalta-se que, para ela, a promoção da alimentação saudável na escola está vinculada ao resgate de um hábito alimentar que é considerado regional e saudável e deve ser perpetuado tendo em vista a prevenção de doenças.

Ao contextualizar que o hábito alimentar regional também é concebido como uma herança que foi perdida ao longo do tempo, vale situar a reflexão de Poulain ${ }^{17}$ quanto ao interesse contemporâneo pelas cozinhas locais. Tal interesse estaria vinculado à nostalgia de um espaço social onde o comensal vivia sem conflitos, ao abrigo de uma cultura culinária claramente identificada. Segundo o autor, nessa perspectiva, as cozinhas locais passam a ser concebidas dentro de um universo considerado tradicional e autêntico, cuja lógica faz emergir o mito do "paraíso culinário perdido", que se contrapõe às transformações e aos ciclos da economia de mercado e representa uma visão edênica da ruralidade, na qual os homens estariam em harmonia entre si e com a natureza. Assim, as tradições alimentares passam a ocupar, de maneira emblemática, um lugar de resistência cultural e identitária ${ }^{17}$.

Nesse sentido, a nutricionista confirma a representação do respeito a esses hábitos no contexto do PNAE e a possibilidade de os alunos sentirem-se estimulados a valorizar a tradição alimentar do lugar, a história de seus antepassados, avôs e pais. Entretanto, ela ressalta que nem "tudo que nossos avôs e bisavôs comiam era saudável", a exemplo de comidas típicas do semiárido, como "buchada e mocotó", que, aos olhos das ciências da nutrição contemporânea, seriam consideradas preparações "ricas em gordura saturada, colesterol", e justifica que nesses casos torna-se incoerente "respeitar" tais hábitos ou programar tais preparações nos cardápios da alimentação escolar.

Para ela, existe também uma desvalorização midiática de determinados produtos, como aqueles que "vêm da roça", significado como lugar de pobre ou sem valor social. Pondera que muitos escolares têm "preconceito" com o que se comia em outras gerações (mungunzá, arroz-doce), considerando como mais interessantes os produtos "novos": biscoito, salgadinho, refrigerante, bala. Apresenta-se, nesse contexto, a relevância das circunstâncias que contribuem para a conformação das identidades sociais desses escolares, nas quais a comida e os alimentos são simbolizados, representados como detentores de status $^{18}$ e marcadores de distinção social ${ }^{19}$, influenciando sua seleção.

A importância do respeito aos hábitos alimentares regionais também é justificada, considerando-se que os alimentos e preparações regionais apresentam potencialmente "boa aceitabilidade" por fazerem parte da tradição e da cultura alimentar, possibilitando assim a "boa" utilização dos recursos públicos. A nutricionista considera que não os respeitar pode gerar um problema de "custo-benefício" por conta de um eventual desperdício devido à incoerência em se inserir no cardápio, por exemplo, um produto "maravilhoso nutricionalmente falando", mas que não é "costume de se comer ali", sendo, portanto, sem sentido para os alunos.

O fornecimento de alimentos habitualmente consumidos como uma estratégia que favorece a aceitação por parte do público beneficiário já é considerado há muito nos programas 
de alimentação e nutrição, como pode ser contextualizado no âmbito do Segundo Programa Nacional de Alimentação e Nutrição (II PRONAN), na década de $1970^{20}$. Anterior aos anos 1980, essa era uma estratégia que visava a ampliar a aceitabilidade dos cardápios de maneira a atender as necessidades nutricionais de grupos vulneráveis biologicamente, que difere da perspectiva atual da garantia do Direito Humano à Alimentação Adequada (DHAA) sob a ótica do respeito à diversidade cultural.

Essa discussão mostra que os alimentos e as preparações que simbolizam/reproduzem o hábito alimentar regional podem ser bem aceitos ou melhorar a adesão à alimentação escolar. Um produto "diferente" do consumido habitualmente, que seja experimentado, provado, pode ter boa aceitabilidade. Não é uma regra geral que a oferta de um alimento ou preparação considerado do hábito alimentar regional seja bem aceito, como no caso do mingau de fubá, que, segundo a nutricionista, foi retirado do cardápio de 2010 pela baixa aceitabilidade. Há ainda as situações em que os alimentos considerados do "hábito alimentar não regional" são bem aceitos, como o cachorro quente.

O respeito aos hábitos alimentares regionais, que estão associados ao resgate de hábitos alimentares saudáveis e à aceitação da alimentação escolar, é significado também como importante por priorizar a agricultura local e valorizar a cultura da região. Dona Marisa, ao ser entrevistada, situou esta perspectiva considerando sua história de vida. O seu pai era agricultor e ela recorda a necessidade de ter a quem vender sua produção, por isso acredita que se deve "dar valor" ao que é produzido na região e mostra seu apreço pela aquisição dos produtos para a alimentação escolar "na mão" dos agricultores locais.

Nina, professora de uma das escolas estudadas, enfatiza a importância da compra da agricultura familiar no PNAE: "porque é um meio de gerar emprego" e valorizar a cultura. Especialmente as merendeiras e diretoras entrevistadas relataram serem muitas vezes os pais dos alunos os próprios agricultores familiares: um fato relevante para que os escolares valorizem a alimentação escolar.

Ao se considerarem as narrativas relacionadas à valorização da produção regional a partir da inserção da agricultura familiar no campo institucional do PNAE, reflete-se sobre a possibilidade em fomentar a identificação dos escolares com a alimentação, favorecendo seu consumo. Essa dimensão simbólica da identificação estaria relacionada, por exemplo, ao valor social que os escolares dariam aos seus pais como produtores dos alimentos consumidos na escola.

Os agricultores familiares, por produzirem alimentos considerados "regionais", ou "da terra", que "se tem conhecimento de onde vêm" e fazem parte da tradição alimentar da região, tornam-se atores fulcrais na instância do respeito aos hábitos alimentares regionais no âmbito do PNAE. Assim, a aquisição desses produtos, compreendidos como "mais saudáveis", "sem tóxico" e "não industrializados", contribui para a efetivação do princípio de respeito ao hábito alimentar regional saudável, que culmina na inclusão de produtos antes não contemplados nos cardápios da alimentação escolar. Entretanto, o alimento produzido por esses agricultores ou empreendedores familiares rurais pode não fazer parte do hábito alimentar regional, como é o caso do iogurte produzido na região estudada, embora seja boa a aceitabilidade nas escolas e possa colaborar com a adesão ao PNAE.

Vale sinalizar que na finalidade da lei sobre a compra dos produtos da agricultura familiar para o PNAE está inscrita a promoção da alimentação saudável e adequada, o respeito à cultura, tradições e hábitos alimentares saudáveis, bem como a possibilidade de fomentar a Segurança Alimentar e Nutricional (SAN) da população. Com isso, objetiva-se o combate à pobreza rural através do fortalecimento da economia local e da geração de emprego e renda. Fica implícito à temática da agricultura familiar no âmbito do PNAE o valor mercadológico que dialoga com a produção formal de alimentos e os valores simbólicos relativos à identidade alimentar. 


\section{ONCLUS Ã O}

O estudo identificou uma complexa polissemia acerca dos hábitos alimentares regionais, cujas acepções dos agentes sociais do PNAE revelaram senso comum e estreito vínculo às vivências sobre o comer e a comida. Dentre as diversas interpretações, observou-se a noção do alimento produzido, plantado, colhido, fabricado na terra, na localidade, no município. Entretanto, outras dimensões aparecem nos discursos.

As preparações ditas habituais nem sempre apresentam em sua composição os produtos "da terra", e, para tanto, emerge o sentido de que tais preparações "sempre" foram consumidas na localidade. Assim, a ideia de permanência, continuidade, frequência e acessibilidade do alimento são expressões imbricadas inexoravelmente ao hábito alimentar regional. Com isso, marcou-se a noção de alimentos tradicionais e, portanto, vinculados a um tempo longínquo e passado, que se perde além da memória, embora possam ser consumidos em outras partes do país e não exclusivamente na região.

Ademais, o hábito alimentar regional é compreendido pelas entrevistadas como "mais saudável e mais natural" por estarem ali abrangidos os alimentos "não industrializados" e produzidos "sem agrotóxicos". Portanto, torna-se importante respeitá-lo no âmbito do PNAE, pois ele pode contribuir para a promoção de hábitos alimentares saudáveis, uma estratégia fundamental para "evitar doenças no futuro". Tal hábito contrapõe-se ao hábito alimentar "não regional", considerado como não saudável e de incorporação recente, não sendo, portanto, genuíno ou autêntico dessa população e região. Para as entrevistadas, é importante o resgate desses hábitos alimentares regionais saudáveis.

Com base em tais interpretações, vale destacar o encontro entre o mito do paraíso culinário perdido e o mito da dieta perfeita e do alimento perfeito. Esses mitos estão circunscritos na acepção do respeito ao hábito alimentar regional, em especial quando ele se torna um "instru- mento" associado à promessa de saúde futura e vinculado à perpetuação de uma herança que deva ser "resgatada" por relacionar-se à produção de um alimento "natural" e à reprodução da cozinha regional, que não pode ser perdida. Nesse sentido, encontra-se no receio da perda um "efeito rebote" à homogeneização da alimentação, característico do processo de globalização. Com isso, constata-se uma resistência para manter as referências conhecidas: há uma necessidade de reafirmação das especificidades culturais e da identidade alimentar, que pode ser visualizada como uma espécie de etnocentrismo culinário, capaz de distinguir espaços e valorizar a cultura dita regional.

Enfatiza-se também a consolidação da contemporânea concepção de alimentação saudável, tida como fulcral para a promoção da saúde e para a prevenção de doenças no mundo. Sinaliza-se, para tanto, a dimensão simbólica do "saudável", na qual estão intrincadas crenças, imaginário, medos e censuras alimentares. Pode-se questionar ainda a acepção expressa pelos entrevistados de que no hábito alimentar regional não estão incluídos os alimentos industrializados. E o que é "industrializado" de fato? Não seriam os doces caseiros, considerados regionais, produzidos com açúcar, um produto que pode ser compreendido como industrializado e não saudável?

Vale ainda refletir acerca da relação entre o alimento regional e o alimento inscrito no hábito alimentar regional. $\mathrm{O}$ alimento regional pode ser produzido na localidade pelos agricultores familiares, por exemplo, e não fazer parte do hábito alimentar regional, como observado em relação ao iogurte. Já o alimento inscrito no hábito alimentar regional pode não necessariamente ser produzido na região, como o arroz. Tais noções aparecem muitas vezes, ao longo das entrevistas, entrecruzadas, levantando dúvidas quanto ao que seria ou não o hábito alimentar regional.

Nesse âmbito, ressalta-se a relevância da acepção temporal para tal delimitação, sendo marcante a ideia de que "sempre foram consumidos", como elucidado nos parágrafos acima. 
Pontua-se, ainda, a possibilidade de os agricultores familiares produzirem alimentos do hábito alimentar regional e a boa aceitabilidade que os produtos não inscritos nesse hábito podem ter no contexto do PNAE.

Sobre hábitos alimentares regionais, o sentido do respeito se conforma quando compreendidos como alimentos saudáveis. Assim, na lógica técnico-nutricional, torna-se um contra-senso programar cardápios da alimentação escolar com preparações não saudáveis, ainda que correspondam à tradição alimentar. Quanto à elaboração desses cardápios, sinaliza-se que o respeito ao hábito alimentar regional se configura objetivamente com a programação de gêneros alimentícios ditos regionais e preparações consideradas como pertencentes ao hábito.

A classificação de ser ou não um alimento regional se encontra intimamente relacionada à experiência do profissional, em suas racionalidades êmica e ética. Sem dissociar esses campos conceituais, a perspectiva da alimentação saudável associa o respeito aos hábitos e a representação de equilíbrio entre os nutrientes no cardápio. Desse modo, as interlocuções entre tais racionalidades geram a possibilidade da criação de um mix entre o regional e o saudável. Assim, observam-se os múltiplos referenciais, relacionados tanto aos aspectos operacionais de execução como aos aspectos ideológico-culturais, com os quais a equipe da alimentação escolar, em especial a nutricionista, deve lidar.

Tendo-se em vista a própria dinâmica cultural contemporânea, pode-se pensar no respeito ao hábito alimentar "glo-cal", ao parafrasear Montanari'12 quando se refere à "cozinha glo-cal". Compreende-se que, de maneira geral, o hábito aponta a possibilidade da "cultura regional não exclusiva", a "mestiçagem" de sistemas de crenças e valores morais, identidades sociais, habitus (sistemas de disposições), signos geradores de identificação: todos eles elementos próprios da diversidade cultural em cada sociedade, como se observa neste estudo no sertão baiano em meio à configuração sociocultural do Brasil.

\section{A GRADECIMENTOS}

Pelo apoio das equipes do Centro Colaborador em Alimentação e Nutrição do Escolar e do Núcleo de Estudos e Pesquisas em Alimentação e Cultura da Universidade Federal da Bahia e da Secretaria Municipal de Educação de Valente Bahia

\section{COLABORADORES}

JB PAIVA participou do planejamento, da execução da pesquisa, da análise e interpretação dos dados e da elaboração e revisão do artigo. MCS FREITAS colaborou na concepção do projeto e com a revisão crítica do artigo. LAS SANTOS participou da concepção, do planejamento e da orientação da pesquisa, da análise e interpretação dos dados e da elaboração e revisão do artigo.

\section{REFERÊ NCIAS}

1. Brasil. Lei $n^{\circ} 11.947$, de 16 de junho de 2009 . Dispõe sobre o atendimento da alimentação escolar e do Programa Dinheiro Direto na Escola aos alunos da educação básica; altera as Leis no 10.880 de 9 de junho de 2004, 11.273, de 6 de fevereiro de 2006, 11.507, de 20 de julho de 2007; revoga dispositivos da Medida Provisória $n^{\circ} 2.178-36$, de 24 de agosto de 2001, e a Lei $n^{\circ} 8.913$, de 12 de julho de 1994; e dá outras providências. Diário Oficial da União. 200917 jun; Seção 1, p.2.

2. Brasil. Resolução FNDE/CD n 38, de 16 de julho de 2009. Dispõe sobre o atendimento da alimentação escolar aos alunos da educação básica no Programa Nacional de Alimentação Escolar - PNAE. Diário Oficial da União. 200917 jul.

3. Spinelli MAS, Canesqui AM. O programa de alimentação escolar no estado de Mato Grosso: da centralização à descentralização (1979-1995). Rev Nutr. 2002; 15(01):105-17. doi: 10.1590/S1415-5 2732002000100011.

4. Bezerra JAB. Regionalização de cardápios, fortalecimento das economias locais e participação da população na gestão descentralizada da merenda escolar. Educ Debate. 2006; 28(51/5):86-93.

5. Chaves LG, Mendes PNR, Brito RR, Botelho RBA. O programa nacional de alimentação escolar como promotor de hábitos alimentares regionais. Rev Nutr. 2009; 22(6):857-66. doi: 10.1590/\$1415-52 732009000600007. 
6. Brasil. Histórico do programa nacional de alimentação escolar. Brasília: FNDE; 2009 [acesso 2010 out 1]. Disponível em: <http://www.fnde.gov.br/ index.php/ae-historico $>$.

7. Belick W, Chaim NA. O programa nacional de alimentação escolar e a gestão municipal: eficiência administrativa, controle social e desenvolvimento local. Rev Nutr. 2009; 22(5):595-607. doi: 10.1590/ S1415-52732009000500001.

8. Instituto Brasileiro de Geografia e Estatística [Internet]. Cidades/Valente, Bahia. [acesso 2011 nov 26]. Disponível em: <http://www.ibge.gov.br/ cidadesat/topwindow.htm?1>.

9. Jovchelovitch S, Bauer M. Entrevista narrativa. In: Bauer M, Gaskell G. Pesquisa qualitativa com texto, imagem e som. 6 ${ }^{a}$ ed. Petrópolis: Vozes; 2007. p.90-113.

10. Minayo MCS. O desafio do conhecimento: pesquisa qualitativa em saúde. $11^{\text {a }}$ ed. São Paulo: Hucitec; 2008.

11. Brasil. Resolução CNS n 196/1996. Aprova diretrizes e normas regulamentadoras de pesquisas envolvendo seres humanos. Brasília: Ministério da Saúde; 1996

12. Montanari M. Comida como cultura. São Paulo: Senac; 2008
13. Fischler C. L'Homnivore. Paris: Odile Jacob, 2001.

14. Lifschitz J. Alimentação e cultura: em torno ao natural. Physis: Saúde Col. 1997 7(2):69-83. doi: 10.1590/S0103-73311997000200005.

15. Santos LAS. O corpo, o comer e a comida: um estudo sobre as práticas corporais e alimentares no mundo contemporâneo. Salvador: EDUFBA; 2008.

16. Carvalho MC, Luz MT. Simbolismo sobre "natural". Ciênc Saúde Col. 2011; 16(1):147-54. doi: 10.1590/S1413-81232011000100018.

17. Poulain J-P. Sociologies de l'alimentation. Paris: PUF; 2002.

18. Contreras Hernández J, Gracia Arnáiz M. Alimentación y cultura: perspectivas antropológicas. Barcelona: Ariel; 2005.

19. Bourdieu P. A distinção: crítica social do julgamento. Barcelona: Ariel, 2005.

20. L' Abbate S. As políticas de alimentação e nutrição no Brasil: II a partir dos anos setentas. Rev Nutr. 1989; 2(1):7-54.
Recebido em: 14/7/2011

Versão final em: 30/11/2011

Aprovado em: 23/3/2012 